\title{
Effect of the CCND1 A870G polymorphism on prostate cancer risk: a meta-analysis of 3,820 cases and 3,825 controls
}

\author{
Min Zheng ${ }^{1}$, Lijun Wan ${ }^{2}$, Xiang He ${ }^{1}$, Xiaolong Qi ${ }^{1}$, Feng Liu and Da-Hong Zhang ${ }^{1 *}$
}

\begin{abstract}
Background: Cyclin D1 (CCND1) is critical in the transition of the cell cycle from the G1 to S phases, and unbalanced cell cycle regulation is a hallmark of carcinogenesis. Numerous epidemiological studies have evaluated the association between the CCND1 A870G polymorphism and the risk of prostate cancer (PCa). However, these studies have yielded conflicting results.

Methods: In the present study, the possible association above was assessed by a meta-analysis. Eligible articles were identified for the period up to July 2014. Pooled odds ratios (ORs) with 95\% confidence intervals (95\% Cl) were appropriately derived from fixed effects or random effects models.

Results: A total of ten case-control studies, which included 3,820 cases and 3,825 controls, were identified. Overall, the allelic/genotypic association between the G870A polymorphism and prostate cancer was nonsignificant $(\mathrm{OR}=1.045,95 \% \mathrm{Cl}=0.947$ to 1.153 for $\mathrm{A}$ versus $\mathrm{G}, P=0.380 ; \mathrm{OR}=1.088,95 \% \mathrm{Cl}=0.896$ to 1.321 for $\mathrm{AA}$ versus $\mathrm{GG}$, $P=0.393 ; \mathrm{OR}=1.044,95 \% \mathrm{Cl}=0.941$ to 1.158 for $\mathrm{GA}$ versus $\mathrm{GG}, P=0.414 ; \mathrm{OR}=1.053,95 \% \mathrm{Cl}=0.955$ to 1.161 for the dominant model $\mathrm{AA}+\mathrm{GA}$ versus $\mathrm{GG}, P=0.303 ; \mathrm{OR}=1.072,95 \% \mathrm{Cl}=0.881$ to 1.306 for the recessive model $\mathrm{AA}$ versus $\mathrm{AA}+\mathrm{GA}, P=0.486)$. Moreover, subgroup analyses according to ethnicity failed to demonstrate a significant association between this polymorphism and prostate cancer. In addition, we also performed a stratified analysis of cases with PCa metastasis, and the results supported the findings of no significant association between CCND1 A870G polymorphism and metastasis risk of PCa.
\end{abstract}

Conclusions: Our results suggest that the CCND1 A870G polymorphism might not be a potential candidate for predicting prostate cancer risk, including metastasis risk.

Keywords: CCND1 A870G, Polymorphism, Prostate cancer

\section{Background}

As one of the most frequent malignant diseases among men, prostate cancer ( $\mathrm{PCa}$ ) is a complex disease that is caused by a multitude of factors [1]. Recently, studies have revealed that genetic factors play an important role in the development of sporadic prostate cancer [2,3], which might provide a potential method for targeted therapy of $\mathrm{PCa}$. Therefore, there is increasing interest in the role that genetic variants such as single nucleotide polymorphic variants (SNPs) play in prostate cancer risk.

\footnotetext{
* Correspondence: urology@zju.edu.cn

'Department of Urology, Zhejiang Provincial People's Hospital, No.158

Shangtang Road, Hangzhou, Zhejiang 310014, China

Full list of author information is available at the end of the article
}

Cell cycle dysregulation plays a critical role in a variety of malignancies and contributes to an increased risk of metastasis, in part, by altering the cell's ability to respond appropriately to DNA damage [4,5]. A number of studies have linked alleles in these genes to increased cancer risk or decreased survival in prostate cancer [6-10]. Cyclin D1, also known as CCND1, is localized to the nucleus and plays a key role in the transition from the G1 to $\mathrm{S}$ phase, which promotes the progression of the cell cycle during cell division [11]. The overexpression of CCND1 has always been observed in numerous types of malignant cancer and indicates a poor clinical outcome [12-14]. Cyclin D1 mRNA is alternatively spliced to transcribe two different transcripts, which yield to functionally different 
proteins [15,16], and an A870G polymorphism in exon4 of CCND1 is involved, alternatively, in splicing of CCND mRNA [15].

Epidemiological studies have reported the association between the CCND1 A/A genotype and the risk of various cancers. Qin et al. found that the CCND1 A/A genotype may increase brain tumor risk, especially for gliomas [17]. Yang et al. also reported that an A870G polymorphism in CCND1 confers an increased risk for breast cancer [18]. However, He et al. revealed that a CCND1 G870A polymorphism has no association with esophageal cancer risk in ethnicity and histology [19]. Although a number of studies have been performed to assess the association between the CCND1 A870G polymorphism and prostate cancer susceptibility, the conclusions have been inconsistent. Wang et al. reported that the A allele of the CCND1 A870G polymorphism was recessively associated with susceptibility to $\mathrm{PCa}[10]$. But no association between the CCND1 A870G polymorphism and prostate cancer was found by Chen et al. [20].

In the present study, ten case-control studies on the CCND1 A870G polymorphism and prostate cancer risk, which were previously published, were analyzed via a metaanalysis to examine a more specific association between the CCND1 A870G polymorphism and prostate cancer risk and various published observational studies.

\section{Methods}

\section{Literature search}

The PubMed, MEDLIN, and Web of Science databases were searched for studies published before July 2014. The key words used for searching were as follows: CCND1/ cyclin D1, prostate cancer/carcinoma/tumor, variant/ genotype/polymorphism/SNP, and the combined phrases for all genetic studies on the association between the CCND1 A870G polymorphism and prostate cancer risk. We also checked the references of the retrieved studies and reviews to ensure the complement of this metaanalysis. This work was approved by the ethics committees of Zhejiang Provincial People's Hospital.

\section{Inclusion criteria}

The following inclusion criteria were used for the literature selection in our meta-analysis: (a) case-control study, (b) evaluation of the CCND1 polymorphism and prostate cancer risk, and (c) sufficient published data for both patients and controls.

\section{Exclusion criteria}

The following exclusion criteria were set: (1) incomplete raw data, (2) repetitive reports (if studies had partly or completely overlapping data, only the largest or most recent sample was selected), (3) materials and methods were not well-described and reliable, or (4) not an English paper.

\section{Data collection}

Two investigators extracted information independently according to the inclusion and exclusion criteria listed. When it came to conflicting evaluations, an agreement was reached after a discussion. For each eligible study, we collected information as follows: the first author's name, publication data, country of origin, sources of controls, number of different genotypes, and ethnicity of the study population (categorized as Asian and Caucasian). For studies including subjects of different ethnic groups, data were extracted separately for each ethnic group whenever possible.

\section{Statistical analysis}

The Hardy-Weinberg equilibrium (HWE) for the control group of each study was assessed using a goodness-of-fit test ( $\chi^{2}$ of Fisher's exact test). Heterogeneity and cumulative analysis were assessed by $\chi^{2}$-based $Q$ test. OR estimation was calculated with the fixed effect model (Mantel-Haenszel method) when statistical heterogeneity did not exist $(P>0.10)$. Otherwise, the random effects model (DerSimonian and Laird method) was selected. Crude odds ratios (ORs) with 95\% confidence intervals (CIs) were used to assess the strength of association between the CCND1 polymorphism and prostate cancer risk. The pooled ORs were performed for a codominant model (GA versus GG and AA versus GG), dominant model (GA/AA versus GG), and recessive model (AA versus GA/GG). Stratified analyses were also performed by ethnicity. Publication bias was evaluated by Funnel plots,

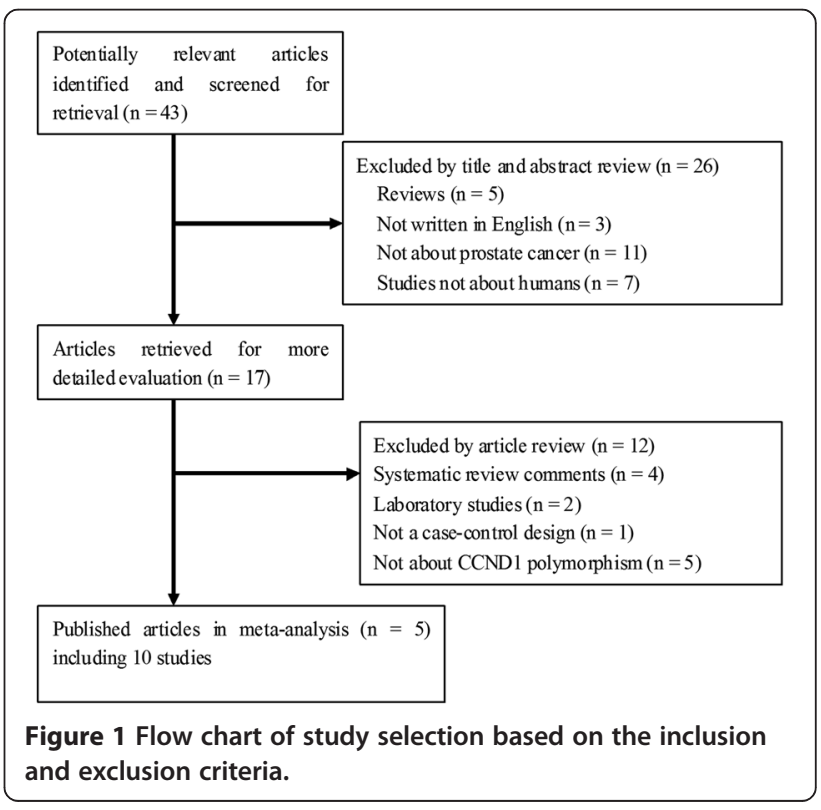


Table 1 CCND1 A870G genotype distribution and allele frequency in cases and controls

\begin{tabular}{|c|c|c|c|c|c|c|c|c|c|}
\hline \multirow[t]{3}{*}{ Author and year } & \multirow[t]{3}{*}{ Ethnicity } & \multirow[t]{3}{*}{ Method } & \multicolumn{6}{|c|}{ Genotype $(N)$} & \multirow{3}{*}{$\begin{array}{l}P \text { HWE } \\
\text { control }\end{array}$} \\
\hline & & & \multicolumn{3}{|c|}{ Case } & \multicolumn{3}{|c|}{ Control } & \\
\hline & & & $\overline{\mathrm{GG}}$ & GA & $\overline{A A}$ & $\overline{\text { GG }}$ & $\mathrm{GA}$ & AA & \\
\hline Wang et al. [10] & Japanese & PCR-RFLP & 55 & 102 & 57 & 75 & 139 & 40 & 0.065 \\
\hline Mandal et al. [24] & Indians & PCR-RFLP & 38 & 65 & 89 & 58 & 93 & 73 & 0.013 \\
\hline Comstock et al. [21] & African-Americans & Taqman & 387 & 258 & 30 & 374 & 246 & 27 & 0.086 \\
\hline Comstock et al. [21] & Latinos & Taqman & 212 & 313 & 118 & 214 & 315 & 117 & 0.954 \\
\hline Comstock et al. [21] & Japanese & Taqman & 121 & 233 & 103 & 126 & 229 & 112 & 0.691 \\
\hline Comstock et al. [21] & Native Hawaiians & Taqman & 14 & 40 & 17 & 12 & 32 & 24 & 0.814 \\
\hline Comstock et al. [21] & European Americans & Taqman & 117 & 242 & 97 & 134 & 225 & 90 & 0.800 \\
\hline Comstock et al. [21] & Australians & Taqman & 241 & 422 & 166 & 225 & 354 & 160 & 0.349 \\
\hline Kibel et al. [22] & Americans & Pyrosequencing & 56 & 88 & 40 & 54 & 100 & 62 & 0.285 \\
\hline Koike et al. [23] & Japanese & PCR-RFLP & 22 & 54 & 23 & 21 & 73 & 21 & 0.004 \\
\hline
\end{tabular}

HWE, Hardy-Weinberg equation; PCR-RFLP, Polymerase chain reaction restriction fragment length polymorphism.

and Begg's test and Egger's test were also used to detect publication bias. Statistical analysis was performed using STATA versions 11.0 (StataCorp, College Station, TX, USA).

\section{Results}

\section{Study characteristics}

After an extensive search, a total of 43 relevant studies were identified (Figure 1). Following a careful review, five published papers with ten case-control studies were identified, with 3,820 patients with prostate cancer and 3,825 controls [10,21-24]. Table 1 presents the main characteristics of those studies, including the distribution of the various genotypes of each study in different populations. A flow diagram schematizing the process of selected and excluded articles with specific reasons for each is presented in Figure 1. All studies are case-control studies. Of these ten studies, three used polymerase chain reaction restriction fragment length polymorphism (PCR-RFLP), six used 5'-nuclease Taqman allelic discrimination assay, and one used pyrosequencing. The studies were carried out in Japan, UK, Australia, and India. Three studies were on Asians and seven studies were on Caucasians. The studies carried out with Japanese were used in the Asian subgroup, and others were used in Caucasian subgroup. The distribution of genotypes in the controls was consistent

Table 2 Meta-analysis of the association between the CCND1 A870G polymorphism and prostate cancer risk

\begin{tabular}{|c|c|c|c|c|c|c|}
\hline \multirow[t]{2}{*}{ Comparisons } & \multirow{2}{*}{$\begin{array}{l}\text { Odds } \\
\text { ratio }\end{array}$} & \multirow{2}{*}{$\begin{array}{l}95 \% \text { confidence } \\
\text { interval }\end{array}$} & \multirow[t]{2}{*}{$P$ value } & \multicolumn{2}{|c|}{ Heterogeneity } & \multirow{2}{*}{$\begin{array}{l}\text { Effects } \\
\text { model }\end{array}$} \\
\hline & & & & $I^{2}(\%)$ & $P$ value & \\
\hline A versus $G$ & 1.045 & 0.947 to 1.153 & 0.380 & 49.7 & 0.037 & Random \\
\hline Asians & 1.100 & 0.891 to 1.358 & 0.374 & 48.8 & 0.142 & \\
\hline Caucasians & 1.026 & 0.911 to 1.157 & 0.669 & 55.8 & 0.035 & \\
\hline AA versus GG & 1.088 & 0.896 to 1.321 & 0.393 & 43.0 & 0.071 & Random \\
\hline Asians & 1.245 & 0.766 to 2.024 & 0.376 & 57.1 & 0.096 & \\
\hline Caucasians & 1.043 & 0.835 to 1.303 & 0.711 & 43.1 & 0.104 & \\
\hline GA versus GG & 1.044 & 0.941 to 1.158 & 0.414 & 0.0 & 0.936 & Fixed \\
\hline Asians & 0.994 & 0.785 to 1.258 & 0.958 & 0.0 & 0.577 & \\
\hline Caucasians & 1.056 & 0.941 to 1.186 & 0.350 & 0.0 & 0.891 & \\
\hline $\mathrm{GA}+\mathrm{AA}$ versus $\mathrm{GG}$ & 1.053 & 0.955 to 1.161 & 0.303 & 0.0 & 0.696 & Fixed \\
\hline Asians & 1.046 & 0.837 to 1.308 & 0.690 & 0.0 & 0.538 & \\
\hline Caucasians & 1.054 & 0.945 to 1.176 & 0.341 & 0.0 & 0.520 & \\
\hline$A A$ versus $G G+G A$ & 1.072 & 0.881 to 1.306 & 0.486 & 59.8 & 0.008 & Random \\
\hline Asians & 1.313 & 0.793 to 2.174 & 0.290 & 72.6 & 0.026 & \\
\hline Caucasians & 1.003 & 0.807 to 1.248 & 0.976 & 56.3 & 0.033 & \\
\hline
\end{tabular}




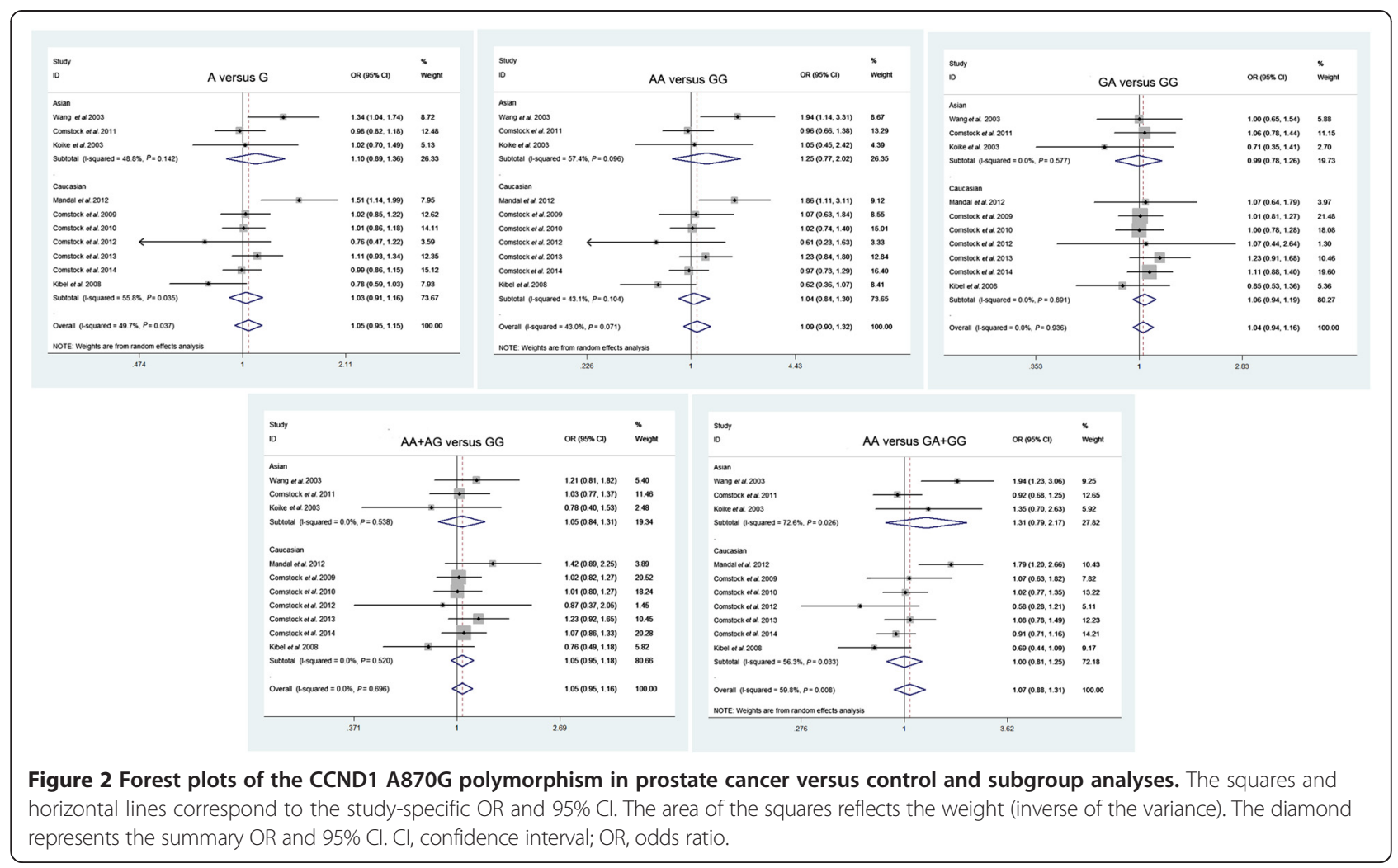

with the Hardy-Weinberg equilibrium $(P>0.05)$ in studies except for Mandal et al. $(P=0.013)$ and Koike et al. $(P=0.004)$.

\section{Quantitative data synthesis}

Table 2 shows the results on the association between the CCND1 A870G polymorphism and prostate cancer risk. The combined results based on all studies revealed that variant genotypes are not associated with increased prostate cancer risk in different genetic models $(\mathrm{OR}=$ $1.045,95 \% \mathrm{CI}=0.947$ to 1.153 for A versus $\mathrm{G}, P=0.380$; $\mathrm{OR}=1.088,95 \% \mathrm{CI}=0.896$ to 1.321 for AA versus $\mathrm{GG}$, $P=0.393$; OR $=1.044,95 \% \mathrm{CI}=0.941$ to 1.158 for $\mathrm{GA}$ versus GG, $P=0.414$; $\mathrm{OR}=1.053,95 \% \mathrm{CI}=0.955$ to 1.161 for the dominant model AA + GA versus GG, $P=0.303$; $\mathrm{OR}=1.072,95 \% \mathrm{CI}=0.881$ to 1.306 for the recessive model AA versus AA + GA, $P=0.486$ ) (Figure 2).
We also performed subgroup analyses by ethnicity, and the results are listed in Table 2. The results revealed no significant associations between the CCND1 A870G polymorphism and prostate cancer in genotype distributions in Asians and Caucasians.

In our present study, we also performed a stratified analysis of cases with PCa metastasis, and the results revealed no significant association between the CCND1 A870G polymorphism and metastasis risk of PCa (Table 3 ).

\section{Heterogeneity analysis}

The following genetic model of the ten studies showed statistically significant heterogeneity using the $Q$ statistic (A versus G: $I^{2}=49.7 \%, P=0.037$; AA versus GG: $I^{2}=$ $43.0 \%, P=0.071$; AA versus GG $+\mathrm{GA}: I^{2}=59.8 \%, P=$ 0.008 ), and the random effects model was employed in these studies. We did not find significant heterogeneity

Table 3 Meta-analysis of the association between the CCND1 A870G polymorphism and metastasis risk of prostate cancer

\begin{tabular}{|c|c|c|c|c|c|c|}
\hline \multirow[t]{2}{*}{ Comparisons } & \multirow{2}{*}{$\begin{array}{l}\text { Odds } \\
\text { ratio }\end{array}$} & \multirow{2}{*}{$\begin{array}{l}95 \% \text { confidence } \\
\text { interval }\end{array}$} & \multirow[t]{2}{*}{$P$ value } & \multicolumn{2}{|c|}{ Heterogeneity } & \multirow{2}{*}{$\begin{array}{l}\text { Effects } \\
\text { model }\end{array}$} \\
\hline & & & & $I^{2}(\%)$ & $P$ value & \\
\hline AA versus GG & 1.072 & 0.645 to 1.782 & 0.788 & 63.3 & 0.066 & Random \\
\hline GA versus GG & 0.842 & 0.513 to 1.382 & 0.496 & 31.2 & 0.234 & Fixed \\
\hline $\mathrm{GA}+\mathrm{AA}$ versus $\mathrm{GG}$ & 0.933 & 0.595 to 1.462 & 0.762 & 48.4 & 0.144 & Fixed \\
\hline$A A$ versus $G G+G A$ & 1.230 & 0.824 to 1.837 & 0.312 & 53.6 & 0.116 & Fixed \\
\hline
\end{tabular}


Table 4 Publication bias test for the CCND1 A870G polymorphism

\begin{tabular}{lllll}
\hline Comparisons & Egger's test & & Begg's test $\boldsymbol{P}$ value \\
\cline { 2 - 3 } & Coefficient & $\boldsymbol{P}$ value & $\mathbf{9 5 \% ~ C l}$ & 0.721 \\
\hline A versus G & 0.191 & 0.889 & -3.171 to 3.554 & 1.000 \\
AA versus GG & 0.156 & 0.909 & -2.899 to 3.210 & 0.371 \\
GA versus GG & -0.640 & 0.249 & -1.829 to 0.548 & 0.721 \\
AA + GA versus GG & -0.329 & 0.674 & -2.067 to 1.409 & 0.721 \\
AA versus GG + GA & 0.709 & 0.678 & -3.083 to 4.500 & \\
\hline
\end{tabular}

for the following model (GA versus AA: $I^{2}=0.0 \%, P=$ 0.936; AA + GA versus GG: $\left.I^{2}=0.0 \%, P=0.696\right)$, and a fixed effects model was performed.

\section{Publication bias}

A Funnel plot and Egger's test were performed to estimate the publication bias of the literature. The Egger-weighted regression method suggested that there was no evidence of publication bias for the CCND1 G720A polymorphism $(P=0.889$ for A versus $G, P=0.909$, for AA versus $G G$, $P=0.249$ for $\mathrm{GA}$ versus $\mathrm{GG}, P=0.674$ for $\mathrm{AA}+\mathrm{GA}$ versus GG, $P=0.678$ for AA versus $\mathrm{GG}+\mathrm{GA})$. This result was confirmed by the Begg's rank correlation method $(P=0.721$ for A versus $G, P=1.000$ for AA versus GG, $P=0.371$ for GA versus $G G$, and $P=0.721$ for $A A+G A$ versus $G G, P=$ 0.721 for AA versus GG + GA) (Table 4, Figure 3).

\section{Discussion}

Cell cycle regulation plays an important role in the evolution of cancer by influencing cell proliferation, differentiation, and apoptosis [25]. CCND1, a key regulatory protein, plays an important role in the transition from the $\mathrm{G} 1$ to $\mathrm{S}$ phase of the cell cycle [15], and its deregulation has been implicated in the pathogenesis of several types of cancers [26,27]. Many polymorphisms have been identified in CCND1. A common functional polymorphism, G870A (rs603965), which increased the frequency of alternative splicing and encoded a protein with an altered C-terminal domain and increased the stability or half-life of the protein, has garnered wide attention. To date, several studies have reported the role of the CCND1 G870A polymorphism in prostate cancer risk [10,22,24]. But the results are controversial, partially because of the possible small effect of the polymorphism on PCa cancer risk. In order to estimate the overall risk of the CCND1 G870A polymorphism associated with prostate cancer, we conducted a meta-analysis of results from ten case-control studies on the association of the CCND1 G870A polymorphism with PCa risk. Overall, a total of 3,820 cases and 3,825 controls were included. However, the results

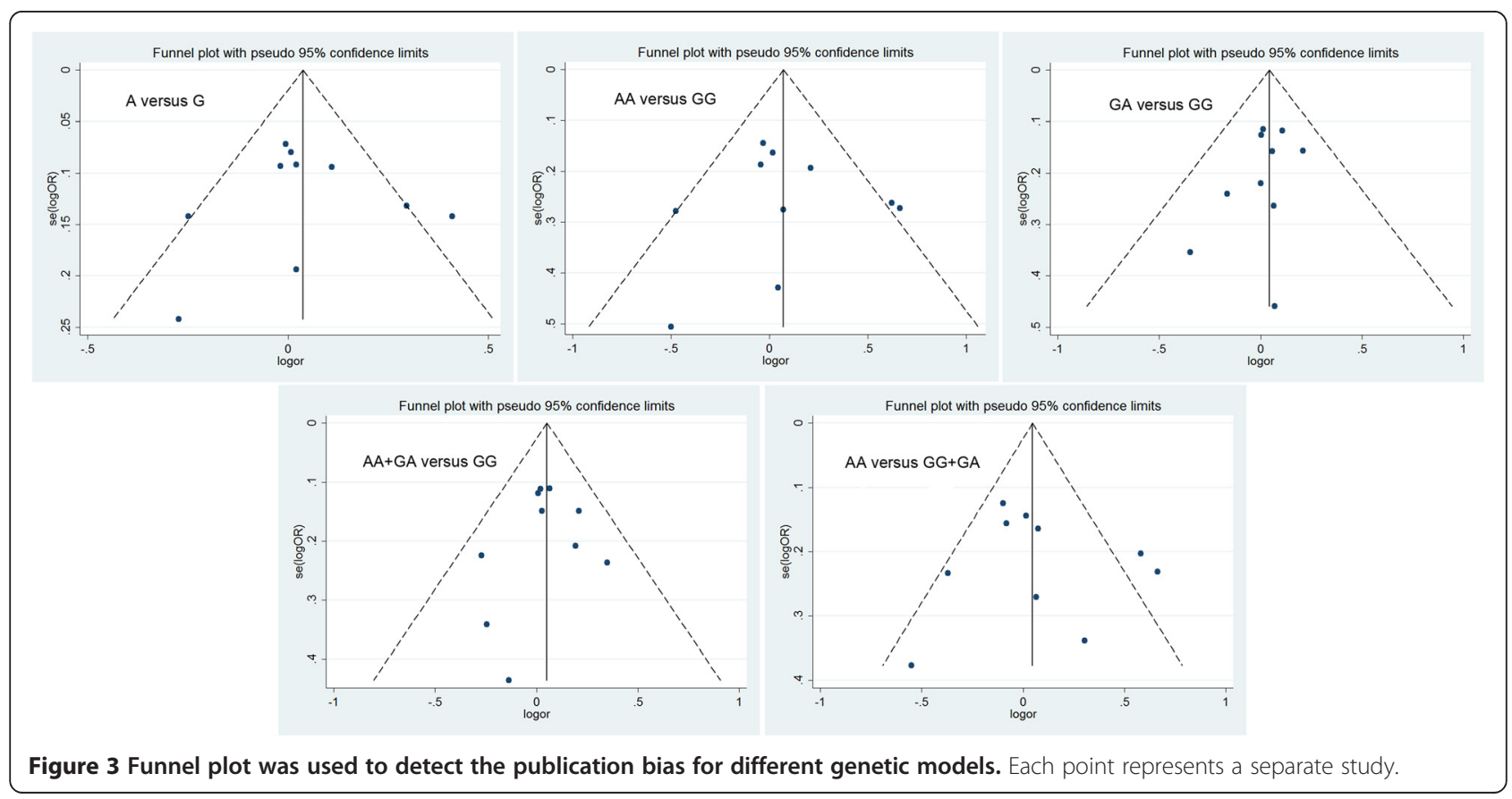


indicated that no significant association between the CCND1 A870G polymorphism and PCa risk was found.

Wang et al. [10] showed that the CCND1 A allele was more frequently observed in the PCa group than the control group, and men with the $A A$ genotype had an increased risk of PCa compared to those with the GG genotype. Mandal et al. [24] also revealed that the CCND1 AA genotype was observed to be associated with a significant increase in PCa risk. However, Koike et al. found that no significant association of the genotype frequency of the CCND1 with overall cases and controls [22]. Our present study showed that no significant association between the CCND1 A870G polymorphism and PCa risk was found.

Stratification analysis showed that the CCND1 A allele showed significantly increased risk of $\mathrm{PCa}$ metastasis [23]. But Mandal et al. did not find any significant risk when analyzing data for the risk of susceptibility for metastasis with the CCND1 polymorphism [24]. In our present study, we also performed a stratified analysis of cases with PCa metastasis, and the results supported the findings that there is no significant association between CCND1 A870G polymorphism and metastasis risk of $\mathrm{PCa}$, as reported by Mandal et al. [24]. But the findings were inconsistent with Koike et al. [23]. Base on the previous studies, the reasons for the discrepancy between our study and previous studies may be various. Genetic heterogeneity is an inevitable problem in any disease identification strategy [28]. Different genetic backgrounds may cause this discrepancy, or different populations may have different linkage disequilibrium patterns. So, we hypothesized that the CCND1 A870G polymorphism might be in close linkage with different nearby causal variants in one ethnic population but not in another, according to the report of $\mathrm{Yu}$ et al. [29]. In addition, a relatively small sample size, the genotyping method, and the prostate cancer type were also identified as potentially significant sources of between-study heterogeneity.

However, some limitations of this meta-analysis should be addressed. First, the results were based on the unadjusted estimates with original data from these collected studies being unavailable, which limited the evaluation with certain covariates, including cancer type, smoking, drinking, age, and other environmental factors. Second, the controls of several studies were various in the analysis, which may have induced the bias of the results and prevented the drawing of more detailed conclusions. Third, the single-locus-based nature of this meta-analysis precluded the possibility of gene-gene and gene-environment interactions; the analysis did not consider these factors because of the lack of sufficient data. Furthermore, we only concentrated on the CCND1 A870G polymorphism and did not evaluate other genes or polymorphisms; whether this polymorphism integrated with other risk factors to enhance the predictive power requires further study.

\section{Conclusions}

In conclusion, we expanded previous individually underpowered studies and suggested that no obvious association was found between the CCND1 A870G and prostate cancer susceptibility. In addition, our observations raise the question of a potential heterogeneous effect of A870G across different ethnic populations. Nevertheless, for practical reasons, we hope that additional studies of CCND1 that include functional DNA repair gene polymorphisms in a large cohort of different ethnicities, combined with more appropriate methods, will augment the etiology of the pathogenesis of PCa.

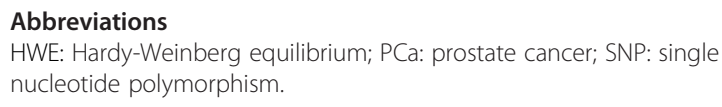

\section{Competing interests}

The authors declare that they have no competing interests.

\section{Authors' contributions}

$M Z$ participated in the design of the study, analyzed the results, and drafted the manuscript. LW participated in the design of the study and performed the statistical analysis. XH and XQ carried out the data research and assessed the results. FL helped to analyze the data and interpret the results. DZ participated in the study design and coordination, revised the manuscript critically, and gave final approval of the version to be published. All authors read and approved the final manuscript.

\section{Acknowledgements}

This work is sported by the Zhejiang Medical College Research Foundation (No. 2013XZB01), National Natural Science Foundation of Zhejiang Province (No. LQ13H050001), and Medicine and Health Research Foundation of Zhejiang Province (No. 2013KYB018).

\section{Author details}

'Department of Urology, Zhejiang Provincial People's Hospital, No.158 Shangtang Road, Hangzhou, Zhejiang 310014, China. ${ }^{2}$ Department of Urology, Quzhou People's Hospital, No. 2 Zhongloudi Street, Quzhou 310014, China.

Received: 11 August 2014 Accepted: 22 January 2015

Published online: 15 February 2015

\section{References}

1. Peters ME, Ostrander EA. Prostate cancer: simplicity to complexity. Nat Genet. 2001:27:134-5

2. Lichtenstein P, Holm NV, Verkasalo PK, Iliadou A, Kaprio J, Koskenvuo M, et al. Environmental and heritable factors in the causation of cancer-analyses of cohorts of twins from Sweden, Denmark, and Finland. N Engl J Med. 2000;343:78-85.

3. Zhang Q, Zheng M, Qi XL, Liu F, Mao ZJ, Zhang DH. Effect of NQ01 C609T polymorphism on prostate cancer risk: a meta-analysis. Onco Targets Ther. 2014;7:907-14.

4. Kibel AS, Isaacs WB. G(1)/S cell cycle proteins as markers of aggressive prostate carcinoma. Urology. 2000;55:316-22.

5. Tomlins SA, Mehra R, Rhodes DR, Cao X, Wang L, Dhanasekaran SM, et al. Integrative molecular concept modeling of prostate cancer progression. Nat Genet. 2007;39:41-51.

6. Chang BL, Zheng SL, Isaacs SD, Wiley KE, Turner A, Li G, et al. A polymorphism in the CDKN1B gene is associated with increased risk of hereditary prostate cancer. Cancer Res. 2004;64:1997-9.

7. Henner WD, Evans AJ, Hough KM, Harris EL, Lowe BA, Beer TM. Association of codon 72 polymorphism of p53 with lower prostate cancer risk. Prostate. 2001:49:263-6.

8. Kibel AS, Suarez BK, Belani J, Oh J, Webster R, Brophy-Ebbers M, et al. CDKN1A and CDKN1B polymorphisms and risk of advanced prostate carcinoma. Cancer Res. 2003;63:2033-6. 
9. Suzuki K, Matsui H, Ohtake N, Nakata S, Takei T, Nakazato H, et al. A p53 codon 72 polymorphism associated with prostate cancer development and progression in Japanese. J Biomed Sci. 2003;10:430-5.

10. Wang L, Habuchi T, Mitsumori K, Li Z, Kamoto T, Kinoshita H, et al. Increased risk of prostate cancer associated with AA genotype of cyclin D1 gene A870G polymorphism. Int J Cancer. 2003;103:116-20.

11. Sherr CJ. Cancer cell cycles. Science. 1996;274:1672-7.

12. Abramson VG, Troxel AB, Feldman M, Mies C, Wang Y, Sherman L, et al. Cyclin D1b in human breast carcinoma and coexpression with cyclin D1a is associated with poor outcome. Anticancer Res. 2010;30:1279-85.

13. Kaminagakura E, Werneck da Cunha I, Soares FA, Nishimoto IN, Kowalski LP. CCND1 amplification and protein overexpression in oral squamous cell carcinoma of young patients. Head Neck. 2011;33:1413-9.

14. Troncone G, Volante M, laccarino A, Zeppa P, Cozzolino I, Malapelle U, et al. Cyclin D1 and D3 overexpression predicts malignant behavior in thyroid fine-needle aspirates suspicious for Hurthle cell neoplasms. Cancer. 2009;117:522-9.

15. Betticher DC, Thatcher N, Altermatt HJ, Hoban P, Ryder WD, Heighway J. Alternate splicing produces a novel cyclin D1 transcript. Oncogene. 1995;11:1005-11.

16. Sawa $\mathrm{H}$, Ohshima TA, Ukita H, Murakami H, Chiba Y, Kamada H, et al. Alternatively spliced forms of cyclin D1 modulate entry into the cell cycle in an inverse manner. Oncogene. 1998;16:1701-12.

17. Qin LY, Zhao LG, Chen X, Li P, Yang Z, Mo WN. The CCND1 G870A gene polymorphism and brain tumor risk: a meta-analysis. Asian Pac J Cancer Prev. 2014;15:3607-12.

18. Yang J, Liu H, Lu S, Gao M, Du Q, Tang SC. Cyclin D1 G870A polymorphism and breast cancer risk: a meta-analysis involving 23,998 subjects. Oncol Res. 2011;19:519-25.

19. He W, Zeng Y, Long J, Zhou Q, Hu Y, Chen M. Genetic polymorphism of G870A and esophageal cancer susceptibility: a meta-analysis. Biomed Rep. 2013;1:303-7.

20. Chen Y, Li T, Yu X, Xu J, Li J, Luo D, et al. The RTK/ERK pathway is associated with prostate cancer risk on the SNP level: a pooled analysis of 41 sets of data from case-control studies. Gene. 2014;534:286-97.

21. Comstock CE, Augello MA, Benito RP, Karch J, Tran TH, Utama FE, et al. Cyclin D1 splice variants: polymorphism, risk, and isoform-specific regulation in prostate cancer. Clin Cancer Res. 2009;15:5338-49.

22. Kibel AS, Jin CH, Klim A, Luly J, Roehl AK, Wu WS, et al. Association between polymorphisms in cell cycle genes and advanced prostate carcinoma. Prostate. 2008;68:1179-86.

23. Koike H, Suzuki K, Satoh T, Ohtake N, Takei T, Nakata S, et al. Cyclin D1 gene polymorphism and familial prostate cancer: the AA genotype of A870G polymorphism is associated with prostate cancer risk in men aged 70 years or older and metastatic stage. Anticancer Res. 2003;23:4947-51.

24. Mandal RK, Mittal RD. Are cell cycle and apoptosis genes associated with prostate cancer risk in North Indian population? Urol Oncol. 2012;30:555-61.

25. Evan $\mathrm{Gl}$, Vousden $\mathrm{KH}$. Proliferation, cell cycle and apoptosis in cancer. Nature. 2001:411:342-8.

26. Knudsen KE, Diehl JA, Haiman CA, Knudsen ES. Cyclin D1: polymorphism, aberrant splicing and cancer risk. Oncogene. 2006;25:1620-8.

27. Musgrove EA, Caldon CE, Barraclough J, Stone A, Sutherland RL. Cyclin D as a therapeutic target in cancer. Nat Rev Cancer. 2011;11:558-72.

28. Hemminki K, Lorenzo Bermejo J, Forsti A. The balance between heritable and environmental aetiology of human disease. Nat Rev Genet. 2006;7:958-65.

29. Yu K, Zhang J, Zhang J, Dou C, Gu S, Xie Y, et al. Methionine synthase A2756G polymorphism and cancer risk: a meta-analysis. Eur J Hum Genet. 2010;18:370-8.

\section{Submit your next manuscript to BioMed Central and take full advantage of:}

- Convenient online submission

- Thorough peer review

- No space constraints or color figure charges

- Immediate publication on acceptance

- Inclusion in PubMed, CAS, Scopus and Google Scholar

- Research which is freely available for redistribution 